\title{
The attribution cube and moral evaluations
}

\author{
DONELSON R. FORSYTH \\ Virginia Commonwealth University, Richmond, Virginia 23284 \\ and \\ WILLIAM R. POPE \\ Mary Washington College, Fredericksburg, Virginia 22401
}

\begin{abstract}
An attribution-based theory of moral evaluations was investigated by systematically varying the distinctiveness, consistency, and consensus of actions that conflicted with or conformed to one of four moral norms (telling the truth, doing one's duty, not stealing, and keeping promises). Analyses of subjects' moral judgments indicated that (1) moral character is assumed to be a prime cause of behaviors that are low in distinctiveness and high in consistency, (2) actions that are high in distinctiveness and low in consistency are less likely to be attributed to the actor's moral character, and (3) consensus information has a lesser impact on moral judgments.
\end{abstract}

Although several theorists have presented attributional perspectives on moral judgments (e.g., Ross \& DiTecca, 1975; Tedeschi, Smith, \& Brown, 1974), Kelley (1971) theorizes that moral evaluations are based on three kinds of attributional data: distinctiveness, consistency, and consensus. Distinctiveness, in the moral realm, is the extent to which an action is unique to the situation. For example, if $\mathrm{X}$ is seen telling a lie, this behavior is nondistinctive if the observer feels that $\mathrm{X}$ also cheats, steals, and breaks promises, but distinctive if the observer feels that $\mathrm{X}$ does not engage in other kinds of morally questionable acts. Consistency is an assessment of action in similar situations in the past. Has X lied before (high consistency over time), or is lying particular to this point in time? Last, consensus information derives from social comparison processes whereby the action is contrasted to the behavior of others in a similar setting. Consensus is high if the attributor feels that anyone would have lied, but it is low if the attributor thinks that few would be untruthful. These three dimensions make up the axes of the attribution "cube," and Kelley (1967, p. 196) predicts that (1) attributors emphasize external causes "when evidence exists as to the distinctiveness, consistency, and consensus of appropriate effects" and (2) attributors emphasize internal causes when the "response is characterized by low consensus, low distinctiveness, and high consistency" (McArthur, 1972, p. 172).

This attributional analysis of moral judgment was investigated by manipulating the consistency, consensus, and distinctiveness of moral and immoral actions. Although overall support for the model was expected, two divergencies from the theory's general predictions

Address reprint requests to Donelson R. Forsyth, Department of Psychology, Virginia Commonwealth University, 810 West Franklin Street, Richmond, Virginia 23284. were also predicted. First, because morally appropriate behaviors are, in general, expected by observers, the impact of consensus data on attributions should be reduced. As Kelley (1971) notes, attributors tend to assume that some behaviors, such as altruism, honesty, or charity, are right, whereas other behaviors, such as murder, lying, or theft, are wrong. In consequence, morally appropriate behaviors are so high in perceived consensus that they do not require an explanation that cites the influence of personal causes. According to this view, consensus estimates of morally appropriate behavior range from moderate to high; the attributor assumes that most people, in most situations, conform to moral norms. In consequence, perceivers ignore situationally defined consensus data and rely primarily on their own prior estimates of consensus.

The second discrepancy between the cube model's general predictions regarding attributions and anticipated effects when applied to moral judgments concerns the impact of consistency over time data. Although attributors generally cite external causes when distinctiveness and consistency are high (Kelley, 1967), these predictions do not hold when consensus data are ignored. For example, if $\mathrm{X}$ tells the truth, moral evaluations should be most positive when the attributor believes that the action stemmed from an internalized sense of morality rather than external pressures. Hence, moral evaluations will be most laudatory when distinctiveness is low (X is also trustworthy and honest) and consistency is high (X always tells the truth). In contrast, attributors should be less favorable if they think external factors caused the truthfulness, but this conclusion is most likely if distinctiveness is high ( $\mathrm{X}$ is untrustworthy and dishonest) and consistency over time is low rather than high (X has lied before). Conversely, if $\mathrm{X}$ tells a lie, then evaluators should be (1) most condemning when the behavior is nondistinctive and consistent and (2) more positive if 
they feel that the action is distinctive and inconsistent with previous actions.

\section{METHOD}

\section{Subjects}

A total of 84 females and 42 males recruited from psychology classes participated in groups that ranged in size from 7 to 10 . All sessions were conducted by a single male experimenter, and all subjects received course credit for participating.

\section{Procedure}

Each subject received a packet of materials containing a consent form, instructions, and questionnaire booklet. Each booklet contained 16 paragraphs, corresponding to the 2 (conformity to the moral norm) by 2 (distinctiveness) by 2 (consistency) by 2 (consensus) factorial design, that described an action performed by $X$. In the first sentence of the paragraph, $X$ 's action was described as either conforming to or violating one of four different moral norms dealing with truthfulness, duty, stealing, or promises. Four different norms were included in the materials to enhance the generalizability of the findings. Subjects were also told to assume that each paragraph referred to a different person.

The remainder of the paragraph presented background information supposedly supplied by an uninvolved bystander. Within the context of this information, the three dimensions of the cube model were varied: (1) Highly distinctive actions differed from the type of action typically performed by $\mathrm{X}$, whereas low-distinctiveness actions were similar to X's other behaviors; (2) high-consistency actions had been performed by $\mathrm{X}$ in the past, whereas low-consistency actions were unlike past behaviors; (3) high-consensus actions were ones that anyone would have performed if in the same situation, whereas lowconsensus actions were described as ones that few people would have undertaken. The 16 paragraphs were presented in a random order, and the sequence of the attribution cube information presented in the paragraphs was varied to control for order effects (Ruble \& Feldman, 1976).

After reading a paragraph, subjects answered the question "How moral do you feel X is?" on a 9-point scale with labeled endpoints $(1=$ very moral and $9=$ very immoral $)$.

\section{RESULTS}

Preliminary analyses revealed no effects of subject gender, so the data were examined in a 4 by 2 by 2 by 2 by 2 repeated-measures analysis of variance that treated moral norm as a between-subjects factor and conformity, distinctiveness, consistency, and consensus as within-subjects factors.

Although several main effects and lower order interactions reached significance, they were qualified by the three-way interaction of conformity, consistency, and distinctiveness $[F(1,123)=10.40, p<.05]$. The means shown in Table 1 indicate that, as predicted, actions were presumed to reflect moral disposition the most in the low-distinctiveness/high-consistency condition. In contrast, actions described in the scenario were least likely to generalize to broad moral evaluations in the high-distinctiveness/low-consistency condition. Overall, attributions were more influenced by distinctiveness information than consistency information. In Table 1, all means differ from each other $(p<.05)$, except low distinctiveness/low consistency (6.47) and high distinctiveness/low consistency (6.66).
Table 1

The Effects of Consistency and Distinctiveness on Moral Judgments of Individuals Who Conformed to or Violated a Moral Norm

\begin{tabular}{|c|c|c|c|c|}
\hline \multirow{3}{*}{$\begin{array}{l}\text { Conformity to } \\
\text { Standard }\end{array}$} & \multicolumn{4}{|c|}{ Consistency } \\
\hline & \multicolumn{2}{|c|}{ High Distinctiveness } & \multicolumn{2}{|c|}{ Low Distinctiveness } \\
\hline & Low & High & Low & High \\
\hline $\begin{array}{l}\text { Conformed to } \\
\text { Violated }\end{array}$ & $\begin{array}{l}6.66 \\
3.71\end{array}$ & $\begin{array}{l}5.82 \\
4.65\end{array}$ & $\begin{array}{l}4.22 \\
6.47\end{array}$ & $\begin{array}{l}2.54 \\
7.29\end{array}$ \\
\hline
\end{tabular}

Note-The greater the mean, the more immoral was the actor. All means except 6.66 and 6.47 are significantly different from each other by Duncan's multiple-range test $(p<.05)$.

The two-way interaction of conformity and consensus also reached significance $[F(1,123)=10.09$, $\mathrm{p}<.05$ ]. When X's behavior conformed to a moral standard, consensus information had no effect on moral judgments: both means were 4.8. However, when X's behavior failed to conform to a standard of morality, high consensus led to somewhat less negative evaluations of $X(p<.05)$; the means were 5.7 for low consensus and 5.4 for high consensus.

\section{DISCUSSION}

Two of the three dimensions of the Kelley attribution cube, consistency and distinctiveness, proved to be powerful determinants of moral judgment. As predicted, attributors assumed that the actor's moral character was reflected in his or her action provided that behavior was low in distinctiveness and high in consistency over time. If, however, the action was both distinctive and low in consistency, attributors were less willing to generalize from observed behaviors to moral dispositions. Also as anticipated, consensus data had less of an impact on moral evaluations. Although high consensus moderated condemnation after violating a moral norm, conforming to a norm even when few others would do so earned the actor no special commendation. These findings suggest an ordering of importance for the three dimensions that, in ranking distinctiveness and consistency ahead of consensus, is consistent with other attributional evidence (e.g., Eisen, 1979; McArthur, 1972).

\section{REFERENCES}

Eisen, S. V. Actor-observer differences in information inference and causal attribution. Journal of Personality and Social Psychology, 1979, 37, 262-272.

Kelley, H. H. Attribution theory in social psychology. In D. Levine (Ed.), Nebraska Symposium on Motivation (Vol. 15). Lincoln: University of Nebraska Press, 1967.

Kelley, H. H. Moral evaluation. American Psychologist, 1971, 26, 293-300.

MCARTHUR, L. A. The how and what of why: Some determinants and consequences of causal attribution. Journal of Personality and Social Psychology, 1972, 22, 171-193.

Ross, M., \& DiTecco, D. An attributional analysis of moral judgments. Journal of Social Issues, 1975, 31, 91-109.

Ruble, D. N., \& Feldman, N. S. Order of consensus, distinctiveness, and consistency information and causal attributions. Journal of Personality and Social Psychology, 1976, 34, 930937.

Tedeschi, J. T., Smith, R. B., \& Brown, R. C., JR. A reinterpretation of research on aggression. Psychological Bulletin, $1974,81,540-563$.

(Received for publication February 7, 1983.) 